\title{
KIYAI SALLEH BIN ABD. KARIM: AMALAN KEBATINAN KUMPULAN SELEMPANG MERAH
}

\author{
(Kiyai Salleh bin Abd Karim: Spiritual Practices by the Red Sash Group)
}

\author{
MUHAMAD SHAFIQ MOHD ALI* \& ABDUL LATIF SAMIAN
}

\begin{abstract}
ABSTRAK
Kumpulan Selempang Merah agak terkenal dengan perjuangan menentang komunis di negeri Johor terutama di bahagian Batu Pahat. Kumpulan ini terkenal dengan menggunakan selempang merah apabila sedang bertempur dengan pihak komunis. Kumpulan ini telah diketuai oleh Kiyai Salleh yang merupakan seorang pejuang untuk mempertahankan kedaulatan agama dan juga bangsanya. Kumpulan Selendang Merah ini telah berjuang menentang kezaliman dan kekejaman komunis dengan hanya menggunakan parang panjang. Di samping menggunakan senjata fizikal, kumpulan ini juga menggunakan ayat-ayat atau zikir-zikir tertentu bagi mensiapkan diri dalam sudut rohani bagi menentang komunis. Terdapat beberapa pendapat menyatakan bahawa ilmu yang diturunkan oleh Kiyai Salleh ini merupakan ilmu pendamping dengan jin kerana peluru yang ditembak oleh komunis kepada mereka tidak lut pada badan dan menyatakan ini merupakan ilmu kebal yang diamalkan oleh ahli kumpulan Selempang Merah. Oleh yang demikian, makalah ini akan membincangkan zikir-zikir dan amalan yang diamalkan oleh kumpulan ini yang diturunkan oleh Kiyai Salleh kepada pengikutnya berdasarkan catatan-catatan yang dibuat oleh beberapa individu yang pernah menemubual ahli kumpulan Selempang Merah dan juga ahli keluarga Kiyai Salleh. Berdasarkan kepada pengumpulan maklumat ini, dapat diperhatikan amalan yang diturunkan oleh Kiyai Salleh merupakan amalan zikir harian dan tidak menyimpang daripada amalan Islam. Amalan ini menjadi pendinding kepada pengamalnya apabila mereka yakin dengan bantuan dan kekuasaan daripada Allah Yang Maha Kuasa.
\end{abstract}

Kata Kunci: Kiyai Salleh; Selempang merah; Komunis; Darurat; Johor

\section{ABSTRACT}

The Red Sash Group is quite notorious for its struggle against the communists in Johor particularly in Batu Pahat. This Group is well known for using the red sash while fighting the communists. This Group was led by Kiyai Salleh a fighter whose intention is to defend the sovereignty of his religion and nation. The Red Sash Group fought against the cruelty of the communists only by using long machetes. Besides the physical weapons, this Group also practiced certain verses and zikr in preparing themselves spiritually to fight against the communits. There is some opinion stated the practice of Kiyai Salleh is an occult practice involving genie companion because they were immuned to ammunition fired by the communists and stated this invulnerability is practiced by the members of the Red Sash. Therefore, this paper will discuss the zikr and practices exercised by this group that Kiyai Salleh passed on to his followers based on the notes made by some individuals who had interviewed the members of the Red Sash Group and the family members of Kiyai Salleh. Based on this information, it is noteworthy that Kiyai Salleh's practice was a daily ritual zikr and did not deviate from Islamic 
practices. This practice is a sort of protector to its practitioners when they believe in the assistance and power of Allah the Almighty.

Keywords: Kiyai Salleh; Selempang merah; Communist; Emergency; Johor

\section{PENDAHULUAN}

Salleh bin Abd. Karim dilahirkan pada tahun 1916 di Tanjung Olak, Bukit Pasir Muar. Bapanya, Abd. Karim bin Kassim seorang India Muslim yang bekerja sebagai buruh kasar manakala ibunya Hajah Lebar bt. Mahmud pula berketurunan Banjar. Salleh mempunyai empat orang adik-beradik, tiga lelaki dan seorang perempuan (Mohd Said 2012). Beliau telah mengukir namanya dengan mendapat gelaran seperti Panglima, Kiyai dan Datuk Penghulu pada tahun antara 1945 hingga 1957. Beliau terkenal dengan perjuangannya menentang kezaliman komunis sewaktu di akhir-akhir penjajahan Jepun dan sewaktu komunis berleluasa pada 1945. Beliau banyak berjuang di daerah Batu Pahat sehingga dianggap wira oleh masyarakat Melayu dan Islam sehingga mendapat anugerah daripada Sultan Johor ketika itu kerana berjaya menyelamatkan masyarakat daripada keganasan yang dilakukan oleh pihak komunis.

Beliau mula menjadi pemimpin kepada gerakan Selempang Merah apabila dilantik sebagai ketua Gerakan Muhammadiah. Beliau telah menggunakan peluang sebagai ketua ini untuk menggunakan segala ilmu kebatinan yang telah dipelajari bagi mempertahankan kedaulatan bangsa dan agamanya. Perjuangan Kiyai Salleh bermula sewaktu beliau sedang solat dan mendengar suara yang menyatakan

\footnotetext{
"kalau kamu tentang pencabulan ini, Tuhan akan berserta kamu, gunakanlah sebarang senjata yang ada pada kamu. Kalau kamu tidak menentangnya harus kamu habis ditindas. Bangunlah menentang di atas daya kamu dan gunalah ayat-ayat al-Quran yang tertentu sebagaimana yang digunakan zaman Rasulullah melawan kafir dahulu dan ayat-ayat yang digunakan dalam perang Sabil zaman Khalifah Islam dahulu".
}

Pasukan yang diketuai oleh Salleh hanya bersenjatakan parang panjang, tombak, lembing dan pedang bagi memerangi pihak Bintang Tiga yang bersenjatakan senapang dan pistol. Pasukan Salleh berjaya menumpaskan pihak Bintang Tiga dengan mudahnya kerana pada penglihatan pihak musuh, pengikut Salleh mempunyai ketinggian seperti pokok kelapa dan mereka menembak ke arah atas (Mohd Said 2012).

Beliau telah kembali ke rahmatullah setelah dirawat di Hospital Besar, Johor Bahru akibat serangan penyakit paru-paru pada 21 April 1959. Jenazah beliau telah disemadikan di tanah perkuburan Islam Bukit Cermai, Batu Pahat. Mungkin agak keterlaluan untuk mengangkat beliau sebagai pejuang kebangsaan kerana perjuangan beliau hanya tertumpu di Batu Pahat sahaja. Namun, dengan jasa beliau yang berjaya menyatupadukan orang Melayu bagi menentang keganasan pihak komunis di Batu Pahat membawa kesan yang amat besar dalam perkembangan sejarah perjuangan politik Johor. Selain dari Johor, beliau juga ada mengajar beberapa orang individu dari luar Johor seperti Perak, Selangor dan beberapa tempat lain.

\section{PENCARIAN ILMU}

Dalam keluarga yang serba kekurangan, beliau hanya mendapat pendidikan sehingga sekolah rendah sahaja di Sekolah Melayu Jorak, Muar. Walaupun begitu, pada siang harinya beliau belajar di sekolah dan malam harinya beliau belajar ilmu persilatan di kampungnya. Pada umurnya menjangkau 13 tahun, ayahnya telah menghantar beliau berguru dengan seorang guru 
agama yang terkenal iaitu, Haji Hussein, Haji Alias, Haji Adam dan Haji Ahmad (Abdul Latip 2012).

Sewaktu belajar di masjid Kg. Ara, Pontian, beliau telah bertemu dengan Kiyai Haji Abdul Fadhil bin Abu Bakar Banten. Beliau telah mempelajari Wirid Khaujakan daripada kiyai ini. Wirid ini merupakan salah satu daripada amalan Tariqat Naqshabandiah. Ia mengandungi ayat al-Quran, zikir dan selawat, Asma'ul Husna dan doa-doa pilihan. Tujuan utama wirid ini adalah untuk pembangunan kerohanian insan bagi mendekatkan diri kepada Allah serta memohon kerahmatan dan keredaan-Nya di dunia dan akhirat (Abdul Latip 2012). Wirid ini dipercayai merupakan amalan daripada jalur amalan Sheikh Abdul Kadir Jailani.

Sewaktu mencari rezeki di Seri Medan, Kiyai Salleh telah berguru dengan seorang alim bernama Tuan Guru Haji Hussein. Haji Hussein telah mengajarkan ilmu gagah, pengasih, kaedah bertahan jika diserang, kaedah untuk menyerang dan juga ilmu mengghaibkan diri ketika musuh datang (Abdul Latip 2012 \& Zaharah Nawawi 1988). Ilmu ini dipanggil ilmu siah palis atau ilmu kebatinan menolak bahaya. Ilmu yang dipelajari daripada Tuan Guru Haji Hussein adalah berdasarkan kepada ayat al-Quran dan hendaklah betul-betul yakin semasa mengamalkannya. Di sini kita dapat melihat bahawa Kiyai Salleh memperoleh ilmunya daripada orang yang membawa amalan yang bersih, tidak bercampur dengan ilmu yang mempunyai pendamping.

\section{AMALAN}

Di sebalik perjuangan dan ajaran daripada Kiyai Salleh, beberapa ajaran telah diterapkan pada pengikutnya. Ajaran ini boleh dibahagikan kepada dua iaitu amalan secara fizikal dan secara kerohanian. Ajaran secara fizikal tidaklah dititikberatkan oleh sebab kebanyakan masyarakat Melayu terutamanya pengikut beliau telah mempunyai pengetahuan tentang ilmu mempertahankan diri terutamanya ilmu persilatan. Selain itu, para pengikutnya juga adalah daripada golongan petani dan juga pencari hasil hutan yang sudah biasa bermain parang atau senjata. Oleh yang demikian, kebanyakan pengikut Kiyai Salleh sudah pandai bermain senjata sekurang-kurangnya pisau.

Bagi amalan kerohanian pula, terdapat ayat-ayat tertentu yang diajarkan oleh Kiyai Salleh terhadap pengikutnya. Amalan yang diajarkan mempunyai waktu beramal yang tertentu. Ada amalan yang dilakukan pada setiap kali selepas solat fardu, ada amalan yang dilakukan sewaktu malam sebelum pergi menyerang, ada amalan dilakukan secara sendirian dan ada juga amalan yang dilakukan secara berjemaah. Antara amalan kebatinan yang diturunkan kepada pengikutnya adalah seperti;

1. Bacaan Yasin 40 kali selepas isyak.

2. Ayat 4

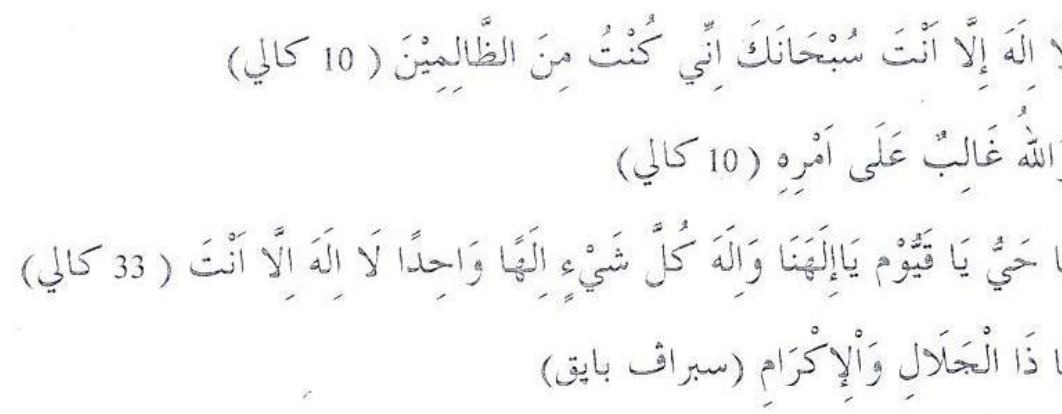

Rajah 1. Susunan Ayat Empat 
Ayat Empat ini perlu diamalkan setiap kali selepas sembahyang lima waktu atau sekurangkurangnya dibaca selepas selesai sembahyang subuh dan maghrib. Khasiat ayat ini sangat besar terutamanya bagi menjaga keselamatan diri dan juga keselamatan keluarga yang mengamalkannya dengan izin Allah.

3. Bacaan semasa berjalan menuju medan perang, sewaktu berperang dan semasa menyerang.

4. Zikir-zikir dan ratib tertentu

5. Sentiasa berwudhu'

6. Selempang yang telah didoakan

Selempang ini merupakan kain merah selebar empat inci dan panjangnya cukup untuk diselempangkan daripada atas bahu kanan hingga ke bawah ketiak kiri. Kain ini telah ditulis ayat al-Quran. Bagi sesiapa yang telah dianugerahkan dengan selempang merah ini, mereka perlu mengikut syarat-syarat yang telah ditetapkan oleh Kiyai Salleh. Pengikut perlu mengikut syarat yang telah ditetapkan untuk menjaga dan menjamin kejayaan ilmu tersebut. Syaratsyarat ini jika dilanggar dikhuatiri akan menghilangkan khasiat ilmu dan boleh menjadi gila (Mohd Said 2012). Antara syarat tersebut adalah;

a. Anggota Selendang Merah boleh memakai selendang itu setiap masa, kecuali waktu mereka pergi ke bilik air atau sewaktu membuang air.

b. Anggota Selendang Merah mestilah mengasap selendang dengan kemenyan sambil membaca takbir setiap petang Jumaat.

c. Anggota Selendang Merah hendaklah menunaikan sembahyang lima waktu walau di mana sekalipun.

d. Anggota tidak boleh berjudi, minum arak, berzina dan membuat sebarang maksiat.

e. Anggota tidak boleh tamakkan harta sewaktu menghadapi peperangan. Tidak dibenarkan mengambil barang-barang yang dijumpai termasuk wang dan perempuan.

f. Anggota tidak boleh melakukan perbuatan zalim terhadap orang yang tidak bersalah.

g. Anggota mesti sentiasa berada dalam keadaan wudhu, terutamanya sewaktu mereka pergi berperang.

h. Taat kepada perintah Allah dan menjauhi segala larangannya.

i. Pemakai tidak boleh bersikap takbur dan bongkak.

j. Digunakan dalam masa kecemasan sahaja.

k. Tidak boleh dibawa ke dalam tandas.

\section{Air yasin yang telah didoakan}

Selain daripada itu, para pengikutnya juga diajarkan supaya menjaga hati daripada sifat tamak. Pengikutnya diarahkan agar tidak mengambil apa-apa barang yang bukan milik mereka kecuali senjata sahaja. Barang siapa yang melanggar syarat ini, dikhuatiri bala akan menimpanya. Selain daripada sifat tamak, para pengikutnya juga dilarang untuk mempunyai sifat-sifat mazmumah. Beliau menyatakan bahawa ta'sub itu salah, ujub dan ria' pun salah. Jauhkan diri daripada berbuat sesuatu yang tidak disukai Tuhan. Terdapat beberapa zikir yang perlu diamalkan oleh pengikut Kiyai Salleh sama ada sebelum dan semasa berperang serta amalan yang perlu dilakukan setiap kali selepas selesai solat fardu. Selain daripada ayat empat, antara zikir lain adalah (Haji Sanif Mun 1978);

1. Ayat penggerun pada pandangan musuh

2. Penolak segala sihir

3. Penawar racun 
4. Doa dihutan, darat dan lautan

5. Petua menguatkan badan dan menundukkan musuh

6. Doa menjaga diri, rumah dan harta

7. Kekuatan semasa kecemasan

Terdapat beberapa pandangan yang menuduh ilmu Kiyai Salleh ini adalah berdampingan dengan jin, oleh sebab itulah mereka kebal. Namun, jika diamati zikir-zikir yang diamalkan hanyalah merupakan zikir harian biasa. Kumpulan yang menuduh ini juga menyatakan air dan selempang merah itu sudah dijampi namun hakikatnya Kiyai Salleh sendiri pernah ditanyakan dengan persoalan ini. Beliau hanya menjawab air dan selempang merah itu hanyalah sebagai pembangkit semangat sahaja. Air dan selempang itu tiada hikmatnya. Hanya zikir dan berserah diri pada Allah sahaja menjadi senjata utama. Ilmu ini juga bukanlah ilmu kebal kerana walaupun ada pihak komunis menyatakan bahawa tiada sebutir peluru pun boleh menembusi Kiyai Salleh, beliau juga pernah tercedera terkena mata tombak pihak musuh di bahunya. Beliau menasihati pengikutnya agar jangan terlalu ta'sub dengan ilmunya kerana terbukti ia bukan ilmu kebal dengan mencontohi dirinya sendiri yang boleh luka terkena senjata tajam. Selain itu, mana-mana pengikutnya yang melanggar pantang juga boleh terkena daripada serangan musuh. Mengasap selendang dengan kemenyan yaria membaca takbir setiap petang Jumaat pula bukanlah petanda amalan ini memohon bantuan daripada jin. Mengasap ini dilakukan untuk memberi bauan yang menarik kerana selendang yang dipakai selalu pasti akan menimbulkan bau yang kurang senang sewaktu memakainya kerana bau daripada peluh si pemakai. Tambahan pula, bauan yang menarik boleh menaikkan lagi semangat juang seperti memakai bau-bauan yang menarik untuk menunaikan solat akan membolehkan si pemakai akan lebih selesa untuk bersolat.

Namun, apa yang menjadi persoalan dalam kajian adalah adakah amalan-amalan yang dilakukan ini benar-benar mengikut lunas dan ajaran agama Islam. Ini kerana dengan hanya menggunakan zikir-zikir tertentu belum menjamin amalan ini patuh 179yariah. Antara perkara asas yang perlu diberi perhatian adalah niat yang terkandung dalam hati para pejuang berkenaan. Jika para pejuang berniat menggunakan ilmu yang diperoleh untuk menjadikan dirinya kebal, ianya salah di sisi Islam. Jika niat para pejuang untuk mendapatkan habuan dunia ianya tidak selari dengan ajaran Islam. Oleh yang demikian apabila diteliti penulisan daripada para pengkaji lepas, kita dapat melihat apakah niat utama para pejuang dalam mengamalkan amalan yang dibawa oleh Kiyai Salleh ini. Temu bual yang dilakukan kepada para pengikut dan juga kepada Kiyai Salleh sendiri menunjukkan bahawa amalan yang diamalkan ini memang niatnya untuk berjuang melawan kumpulan komunis. Ini kerana amalan ini apabila dilakukan di luar waktu berjuang melawan komunis, ianya tidak mujarab. Di samping itu, amalan ini juga diyakini bukan ilmu kebal kerana Kiyai Salleh juga pernah tercedera terkena mata tombak pihak musuh di bahunya. Beliau menasihati pengikutnya agar jangan terlalu ta'sub dengan ilmunya kerana terbukti ia bukan ilmu kebal dengan mencontohi dirinya sendiri yang boleh luka terkena senjata tajam.

\section{ILMU KEROHANIAN}

Setiap bangsa mempunyai kepercayaan dan juga kaedah kerohanian tersendiri. Anuar Abd Wahab (2008) menyatakan setiap jenis kerohanian ini berpandukan kepada latar kepercayaan, pengetahuan, pengalaman dan budaya bertujuan untuk mewujudkan hubungan antara manusia dan alam ghaib setiap bangsa tersebut. Abdul Rahman (2009) menyatakan aspek kebatinan merupakan perkara yang bersangkutan dengan alam ghaib, alam yang tidak dapat dibuktikan secara empirikal atau secara uji kaji sains. Abdul Rahman (2009), menulis dalam karyanya Seni 
Silat Melayu, Sejarah Perkembangan dan Budaya tentang ilmu-ilmu kebatinan yang terdapat dalam teks-teks Melayu klasik. Beliau berpendapat, berdasarkan teks Melayu tradisional tersebut terdapat kemungkinan wujudnya amalan ilmu kebatinan dalam Seni Silat Melayu.

Namun, menjadi persoalan pada kebanyakan orang, adakah ilmu kerohanian atau kebatinan ini tidak melanggar hukum agama Islam. Ilmu kerohanian orang Melayu boleh ditelusuri daripada sebelum orang Melayu mempunyai pegangan agama lagi. Dalam jiwa masyarakat Melayu sebelum menganut sesuatu agama telah tumbuh kepercayaan dengan melihat alam sekelilingnya dan juga wujudnya soal hidup dan mati (Abdul Malik 1961). HAMKA menyebut bahawa pengaruh animisme wujud apabila manusia hidup dikelilingi alam dan mendapat pengaruh daripada air, tanah, api dan angin yang membawa kebaikan atau bencana pada mereka. Tindakan alam yang memberi kesan dalam kehidupan manusia membawa kepada konsep nasib tuah malang dan sial pada manusia.

Seseorang yang ingin membuang sial atau nasib malang, perlu melakukan ritual tertentu untuk membuang nasib malang tersebut. Anuar Wahab (2008) menyatakan orang yang menjadi perantaraan melakukan puja dan ungkapan pemujaan yang disebut mantera dipercayai dapat berhubungan dengan makhluk halus atau semangat bagi menyampaikan segala hasrat. Supaya lebih mujarab, mereka akan dipakaikan dengan tangkal, azimat, kayu, tulang, taring, kulit dan batu yang dianggap mempunyai kesaktian dan penjaga yang boleh memberi manfaat kepada pemakainya. Selain daripada tangkal, seseorang juga diberi jampi serapah untuk digunakan ketika menghadapi masalah seperti gangguan alam, haiwan dan juga sesama manusia. Jampi serapah ini mempunyai tujuan yang tertentu seperti pelemah, pelimun, pengasih, penggerun, naik semangat, kebal, apung, penimbul, menghalau, menangkap makhluk halus dan sebagainya (Anuar Wahab 2008). Pemujaan, penggunaan tangkal dan juga jampi serapah ini mewujudkan amalan, pantang larang dan syarat sebagai menjaga diri daripada melakukan perkara yang boleh membatalkan atau melemahkan kuasa, amalan, kesaktian, ilmu dan amalannya.

Anuar Wahab (2008) juga menyatakan kerohanian adalah ilmu yang bersangkutan dengan soal roh, nyawa, jiwa atau batin. Perkara ini telah mempengaruhi pembentukan nilai, sifat dan sikap orang Melayu. Masyarakat prasejarah telah mempunyai kepercayaan bahawa alam sekeliling memberi pengaruh dalam kehidupan mereka. Oleh yang demikian, timbullah kepercayaan terhadap tuah dan sial, hantu puaka, makhluk halus serta semangat padi, matahari, laut dan lain-lain. Setelah itu, kehadiran pengaruh Buddha-Hindu di Alam Melayu turut menyumbang kepada perkembangan ilmu kerohanian masyarakat Melayu dengan diperkenalkan dewa-dewa yang menguasai alam dan kehidupan. Daripada pengaruh kepercayaan terhadap dewa dewi ini, timbullah segala macam unsur kesaktian, mantera, peraturan, pantang larang, azimat, tangkal yang boleh membantu ketika diperlukan.

Kehadiran Islam telah menyebabkan masyarakat Melayu meninggalkan perlahan-lahan kepercayaan terhadap dewa dewi Buddha-Hindu. Para ulama' mengajar masyarakat Melayu untuk mempercayai keesaan Allah dengan segala nama dan sifatnya. Islam telah mengajarkan masyarakat Melayu berkenaan iman, akidah, ibadah, akhlak dan ilmu pengetahuan bersumberkan kepada ilmu wahyu dan sunnah. Kedatangan Islam telah menyusun tatacara kehidupan masyarakat Melayu supaya lebih baik dengan segala sifat baik yang diajarkan oleh ulama. Segala mantera dan tangkal segera ditinggalkan dan hanya berpegang kepada keyakinan kepada bantuan Allah di samping mengamalkan doa-doa pilihan.

Oleh kerana Kiyai Salleh mengetahui banyak ilmu kebatinan, beliau sering dikunjungi orang ramai seluruh Tanah Melayu antara 1946 hingga 1950. Setiap hari, Kiyai Salleh menerima 30 hingga 50 orang pengunjung ke rumahnya bertujuan untuk menuntut ilmu kebatinan dan ilmu kependekaran. Selain itu, ada juga pengunjung yang datang untuk meminta air jampi, pendinding diri dan rumah, air penerang hati, ubat pengasih dan lain-lain hajat. Di samping itu, pengunjung yang datang bermohon hajat dengan beliau bukanlah daripada kaum Melayu sahaja, terdapat juga pengunjung Cina dan India datang untuk meminta ubat (Mohd 
Said 2012). Mohd Said juga menulis Kiyai Salleh pernah mengubati seorang yang mempunyai penyakit gila berketurunan Cina. Orang Cina ini juga tinggal bersama beliau di rumahnya sehinggalah penyakit gilanya sembuh.

\section{RUJUKAN}

Abdul Latip Talib. 2012. Kiyai Salleh. Shah Alam, Selangor: PSN Publications Sdn. Bhd.

Abdul Malik Karim Amrullah. 1961. Sejarah Umat Islam. Jakarta: Pustaka Antara.

Abdul Rahman Ismail. 2009. Seni Silat Melayu, Sejarah Perkembangan dan Budaya. Kuala Lumpur: Dewan Bahasa \& Pustaka.

Anuar Abdul Wahab. 2008. Silat, Sejarah Perkembangan Kurikulum Silat Melayu Tradisi Dan Pembentukan Kurikulum Silat Malaysia Moden. Selangor: Pertubuhan Seni Gayung Fatani Malaysia.

Hairi Abdullah. 1973/75. Kebangkitan dan gerakan tentera Selendang Merah dalam sejarah daerah Muar dan batu Pahat. JEBAT 3/4: 6-15.

Haji Sanif Mun. 1978. Amalan Kota Negara. Johor Bahru: Al-Ahmadiah Press Sdn. Bhd.

Mohd Said Jamhari. 2012. Panglima Penghulu Kiyai Salleh Bin Abd. Karim. Dlm. Pengemudi Bahtera Merdeka Johor. Disunting oleh Abu Bakar A. Hamid, Md Ismail Zamzam \& Kamdi Kamil, pp: 273-286. Johor Baru: Yayasan Warisan Johor.

Zaharah Nawawi. 1988. Panglima Salleh: Selempang Merah. Kuala Lumpur: Dewan Bahasa \& Pustaka.

MUHAMAD SHAFIQ MOHD ALI

Institut Alam dan Tamadun Melayu (ATMA)

Universiti Kebangsaan Malaysia

E-mel: muhdshafiq@ukm.edu.my

ABDUL LATIF SAMIAN

Institut Alam dan Tamadun Melayu (ATMA)

Universiti Kebangsaan Malaysia

E-mel: abdlatif@ukm.edu.my

*Pengarang untuk surat menyurat: muhdshafiq@ukm.edu.my 